\title{
Inhibition of Vascular Smooth Muscle Cell Proliferation In Vitro and In Vivo by C-myc Antisense Oligodeoxynucleotides
}

\author{
Martin R. Bennett, ` Sandra Anglin, ${ }^{\ddagger}$ Jean R. McEwan, ${ }^{\star}$ Roger Jagoe, ${ }^{\star}$ Andrew C. Newby, ${ }^{\star}$ and Gerard I. Evan \\ ${ }^{*}$ Department of Cardiology, University of Wales College of Medicine, Cardiff CF $44 X N ;{ }^{\ddagger}$ Department of Clinical Pharmacology, Royal \\ Postgraduate Medical School, London W12 ONN; and ${ }^{\S}$ Biochemistry of the Cell Nucleus Laboratory, Imperial Cancer Research Fund, \\ London WC2A 3PX, United Kingdom
}

\begin{abstract}
Restenosis after angioplasty is due predominantly to accumulation of vascular smooth muscle cells (VSMCs). The resistance of restenosis to pharmacological treatment has prompted investigation of genes involved in VSMC proliferation. We have examined the effect on VSMC proliferation of blocking expression of the c-myc proto-oncogene with antisense oligodeoxynucleotides, both in vitro and in a rat carotid artery injury model of angioplasty restenosis. Antisense c-myc oligodeoxynucleotides reduced average cell levels of c-myc mRNA and protein by 50 55\% and inhibited proliferation of VSMCs when mitogenically stimulated from quiescence or when proliferating logarithmically $\left(\mathrm{IC}_{50}=10 \mu \mathrm{g} / \mathrm{ml}\right)$. Corresponding sense c-myc, two-basepair mismatch antisense c-myc, antisense $\alpha$-actin or glyceraldehyde phosphate dehydrogenase oligodeoxynucleotides did not suppress c-myc expression or inhibit VSMC proliferation. Antisense c-myc inhibition was relieved by overexpression of an exogenous c-myc gene. After balloon catheter injury, peak cmyc mRNA expression occurred at $2 \mathrm{~h}$. Antisense c-myc applied in a pluronic gel to the arterial adventitia reduced peak c-myc expression by $75 \%$ and significantly reduced neointimal formation at $14 \mathrm{~d}$, compared with sense c-myc and gel application alone. We conclude that c-myc expression is required for VSMC proliferation in vitro and in the vessel wall. C-myc is a therefore a potential target for adjunctive therapy to reduce angioplasty restenosis. (J. Clin. Invest. 1994. 93:820828.) Key words: angioplasty $\bullet$ antisense $\cdot$ c-myc $\bullet$ smooth muscle
\end{abstract}

\section{Introduction}

Restenosis after coronary angioplasty remains a significant clinical problem with $>30 \%$ restenosis rates at $6 \mathrm{mo}$ (1). The restenosis is caused predominantly by an accumulation of vascular smooth muscle cells (VSMC) (1), ${ }^{1}$ extracellular matrix,

Dr. Anglin's and Dr. McEwan's present address is Hatter Institute for Cardiovascular Studies, University College London Medical School, London WCIE 6AU, UK.

Address reprint requests to Dr. Martin R. Bennett, Department of Pathology, SJ-60, University of Washington, Seattle, WA 98195.

Received for publication 20 April 1993 and in revised form 14 September 1993.

1. Abbreviations used in this paper: GAPDH, glyceraldehyde phosphate dehydrogenase; $\alpha$-sm-actin, $\alpha$-smooth muscle actin; VSMC, vascular smooth muscle cells.

J. Clin. Invest.

(c) The American Society for Clinical Investigation, Inc.

0021-9738/94/02/0820/09 \$2.00

Volume 93, February 1994, 820-828 and collagen (2). Many pharmacological inhibitors of VSMC proliferation have been identified in vitro, and some, including heparin, angiotensin-converting enzyme inhibitors, and interferon- $\gamma$, have also been found to inhibit the neointima that leads to restenosis in vivo, in animal models of arterial restenosis (3-8). However, no agent has yet been found that successfully inhibits angioplasty restenosis in human trials (see reference 9 for review). Recent research has therefore examined the potential of using antisense oligodeoxynucleotides to identify genes whose expression is important in VSMC proliferation as a step toward novel therapy. Antisense oligodeoxynucleotides are short synthetic DNA molecules whose sequences are complementary to those present in specific target mRNAs within cells. Antisense oligonucleotides complementary to sequences in the proto-oncogene c-myb and the genes for nonmuscle myosin and proliferating cell nuclear antigen have all been found to reduce arterial proliferation in vitro (10-12). In addition, antisense $c-m y b$ oligonucleotides can also reduce neointimal formation in vivo (13).

The c-myc oncogene is homologous to the transforming gene of the avian myelocytoblastosis virus MC29 and has long been implicated in the control of normal and abnormal cell proliferation (14). C-myc encodes a short-lived sequence-specific DNA-binding nuclear phosphoprotein thought to be involved in transcriptional modulation. Mitogen stimulation of quiescent VSMCs rapidly induces c-myc with a peak of expression at 2-4 h $(15,16)$. Subsequently, c-myc expression in VSMCs is maintained at a constant low level throughout the first and subsequent cell cycles (17). C-myc thus appears to have a role both in entry into the cell cycle and in the maintenance of cell proliferation. Consistent with this, we have recently shown that c-myc down-regulation is an essential component of the antiproliferative action of a variety of VSMC growth inhibitors (18). The constant requirement for low level expression of $c-m y c$ in proliferating VSMCs and the short halflife of c-myc mRNA and protein all conspire to make c-myc an attractive target for antisense inhibition. Indeed, antisense c$m y c$ oligonucleotides have previously been shown to reduce proliferation and/or increase differentiation in a number of cell lines (19-24).

Recently antisense c-myc oligonucleotides have been demonstrated to exert antiproliferative effects on animal and human VSMCs in vitro $(25,26)$ but no study has examined the effects of antisense c-myc oligonucleotides on VSMCs in vivo. We have therefore used an antisense c-myc oligodeoxynucleotide analogue, previously demonstrated to be stable in culture, to enter cells and form hybrid duplexes, and to reduce c-Myc protein levels (20), and examined its effects on the proliferation of VSMCs both in vitro and in vivo using a rat carotid artery injury model of restenosis. We have also examined the effects of antisense sequences complementary to sequences in genes not directly related to the proliferative process $(\alpha$-smooth 
muscle actin [ $\alpha$-sm-actin] and glyceraldehyde phosphate dehydrogenase [GAPDH]).

\section{Methods}

Cell culture. VSMCs were isolated from thoracic aortic explants of 6-wk-old Sprague-Dawley rats. Cells were cultured in DME containing 10\% FCS (Gibco, Grand Island, NY) 20 mM Hepes (Flow Laboratories, Melcan, VA) and equilibrated with $95 \%$ air and $5 \% \mathrm{CO}_{2}$. Subconfluent cells were passaged by trypsinization in $0.05 \%$ trypsin in PBS and reseeded in DME + 10\% FCS (normal culture medium). VSMCs were identified by their typical "hill and valley" morphology in culture and by immunocytochemical staining for $\alpha$-sm-actin (Sigma Chemical Co. [St. Louis, MO] monoclonal anti-sm-muscle $\alpha$-actin antibody). Cells at passage 5 were used for experiments and retroviral infections.

Production of VSM-myc cell lines. The retroviral vectors used to generate VSMC lines that constitutively express elevated c-Myc protein levels (VSM-myc cells) were constructed by inserting a full-length human c-myc cDNA into the pDORneo retroviral vector (27). This vector contains the Moloney murine leukemia virus long terminal repeat which drives expression of the c-myc sequence and an internal Simian virus 40 (SV40) promoter from which the neomycin resistance gene is expressed. Normal rat VSMCs were plated in $90-\mathrm{mm}$ tissue culture plates at a density of $2 \times 10^{7}$ cells per plate and left in normal culture medium for $24 \mathrm{~h}$. The medium was then aspirated and replaced with $2 \mathrm{ml}$ of medium containing virus (the supernatant of a $90-\mathrm{mm}$ plate of GP + E packaging cells harvested at $48 \mathrm{~h}$ after infection) diluted at 1:50 in media and $8 \mu \mathrm{g} / \mathrm{ml}$ of polybrene at $37^{\circ} \mathrm{C}$ for $2 \mathrm{~h}$. This medium was then aspirated and replaced with $10 \mathrm{ml}$ of normal medium for $24 \mathrm{~h}$. The cells were then trypsinized, split 1:20, and cultured in normal medium for $24 \mathrm{~h}$. The following day, $500 \mu \mathrm{g} / \mathrm{ml}$ of G418 (Genticin; Gibco) was added to the growth medium and resistant clones were selected. Individual clones were picked, plated into individual flasks, and cultured in medium containing $500 \mu \mathrm{g} / \mathrm{ml}$ of G418. A clone of VSM-myc cells was used which constitutively expressed 7 $\times$ normal $\mathrm{c}-\mathrm{Myc}$ protein levels as assessed by c-Myc protein ELISA (28). Absolute levels of intracellular c-Myc protein expression were determined using a bacterially expressed c-Myc protein as standard (28) and see below.

Synthesis and purification of oligodeoxynucleotide. Phosphorothioate-derivatised oligodeoxynucleotides were synthesized on an automated synthesizer (model 380B, Applied Biosystems Inc., Foster City, CA). After deprotection, oligodeoxynucleotides were dissolved in water, extracted with phenol/chloroform/isoamyl alcohol (49.5:49.5:1), precipitated with ethanol, and redissolved in water. Concentrations were determined spectrophotometrically by assuming $1 A_{260}$ unit $=33$ $\mu \mathrm{g}$ RNA. All oligodeoxynucleotides used were 15-mers. The c-myc sense oligodeoxynucleotide sequence comprised the first 5 codons of human c-myc mRNA (5' ATGCCCCTCAACGTT 3') and antisense c-myc oligodeoxynucleotides comprised the complementary sequence AACGTTGAGGGGCAT. Other oligodeoxynucleotides used were $(a)$ a 2-bp internal mismatch antisense c-myc sequence (2-bp internal mismatch) (5' AACGTGGAGTGGCAT 3'); (b) a sequence complementary to the first 5 codons of rat (GAPDH) mRNA ( $5^{\prime}$ ACCGACCTTCACCAT $3^{\prime}$ ); and $(c)$ a sequence complementary to part of the $5^{\prime}$ noncoding sequence of rat VSMC $\alpha$-sm-actin mRNA ( $5^{\prime}$ ATGGCGACTGGCTGG 3'). The $\alpha$-sm-actin sequence was chosen on the basis of minimal complementarity to sequences in either $\beta$ - or $\gamma$-actin gene isoforms.

Cell proliferation studies. To determine VSMC proliferation, VSMCs were plated into 24 -well plates at $1 \times 10^{4}$ cells/well and cultured in DME + 0.5\% FCS for $72 \mathrm{~h}$ (day 0 ). The medium was then replaced with DME $+10 \%$ FCS alone or with $5-30 \mu \mathrm{g} / \mathrm{ml}$ of antisense c-myc oligodeoxynucleotides or $30 \mu \mathrm{g} / \mathrm{ml}$ of one of the other oligodeoxynucleotide sequences. Triplicate wells were trypsinized to release cells and the cells counted by trypan blue exclusion on a hemocytometer at appropriate time points. To study proliferation of logarithmic phase cells, VSMCs were plated into 24-well plates at $1 \times 10^{4}$ cells $/$ well and cultured in DME + 10\% FCS for $48 \mathrm{~h}$ (day 0). 5-30 $\mu \mathrm{g} / \mathrm{ml}$ of antisense c- $m y c$ or $30 \mu \mathrm{g} / \mathrm{ml}$ of one of the other oligodeoxynucleotide sequences were then added to the media of triplicate wells and cell number counted as above at appropriate time points.

Rat carotid artery model of intimal hyperplasia. Intimal hyperplasia was induced by balloon catheter dilatation of the carotid artery of the rat. Male rats $(300-350 \mathrm{~g})$ were anesthetized by intraperitoneal injection of fentanyl (Janssen Pharmaceutica) and midazolam (Roche) and the neck was incised. Left common carotid injury was induced by the passage of a Fogarty balloon embolectomy catheter (FG2) (Baxter Healthcare Corp., Deerfield, IL), inserted via the left external carotid artery and distended with $20 \mu \mathrm{l}$ of saline as described by Clowes et al. (29). In experiments designed to examine the time course of c-myc induction after injury, the left common carotid artery was injured, the neck wound was repaired, but the rats were kept under anesthesia until they were killed by exsanguination 1-4 h later. Injured left and uninjured right common carotid arteries were removed and snap-frozen in liquid nitrogen for RNA extraction. In studies examining the effect of antisense oligodeoxynucleotides on c-myc mRNA expression, antisense c-myc $(n=6)$ or sense c-myc $(n=6)$ oligodeoxynucleotides were applied to the adventitial surface of the arterial wall in a pluronic gel solution. Sense and antisense c-myc oligodeoxynucleotides were dissolved in a $0.25 \%$ pluronic gel solution at $4^{\circ} \mathrm{C}(\mathrm{F} 127$, BASF Corp.) at $1 \mathrm{mg} / \mathrm{ml} .200 \mu \mathrm{l}$ of the gel solution was applied to the distal third of the common carotid artery, immediately after vessel injury, as described by Simons et al. (13). The animals were kept under anesthesia and the artery removed $2 \mathrm{~h}$ later for RNA extraction. In studies examining the neointimal response to injury, $200 \mu \mathrm{g}$ of antisense c-myc $(n=9)$ or sense c-myc $(n=5)$ oligodeoxynucleotides were applied as above immediately after injury. Pluronic gel alone was applied to further injured vessels $(n=5)$. The neck wounds were then repaired and the animals allowed to recover. $14 \mathrm{~d}$ after injury, the rats were reanesthetised and killed by exsanguination through an aortic cannula, and the carotid artery was fixed in situ by perfusion with $1 \%$ paraformaldehyde and $2 \%$ glutaraldehyde at $120 \mathrm{mmHg}$ perfusion pressure for $10 \mathrm{~min}$. The left and right common carotid arteries were excised and placed in the same fixative for a further $16 \mathrm{~h}$ before processing and embedding in Araldite epoxy resin. $2-\mu \mathrm{m}$ sections were stained with toluidine blue and the cross-sectional area of neointima measured for the proximal (untreated) and distal ( treated) thirds of the artery. A cross section of the artery was examined microscopically and viewed using a $\times 4$ objective. The image was digitized by a ContextVision Gop-302 image analysis computer using the green channel of a JVC-M280 TV camera mounted on the microscope. The image area corresponded to $2.1 \mathrm{~mm}^{2}$ of the section. Using a mouse-controlled cursor, the boundaries of the intima and media were traced onto the image display. The area of each traced region and the mean distance between neighboring boundaries were calculated.

RNA isolation and Northern hybridization. Total RNA from cultured cells was isolated by the method of Chirgwin et al. (30). 107 normal rat VSMCs were grown in DME + $10 \%$ FCS until $50 \%$ confluent. $30 \mu \mathrm{g} / \mathrm{ml}$ of sense c-myc, antisense c-myc, 2-bp mismatch antisense c- $m y c$, antisense $\alpha$-sm-actin, or antisense GAPDH oligodeoxynucleotides were then added to the medium and RNA isolated from cells after $24 \mathrm{~h}$. PolyA ${ }^{+}$RNA was isolated from whole rat carotid arteries using the Micro-Fast Track System (Invitrogen). RNA was quantified spectrophotometrically. $15 \mu \mathrm{g}$ of total RNA or $0.5 \mu \mathrm{g}$ of polyA ${ }^{+}$RNA per time point was electrophoretically fractionated on a $1 \%$ agarose gel containing $2.2 \mathrm{M}$ formaldehyde in a $1 \times$ Mops running buffer $(200 \mathrm{mM}$ 3-( $N$-morpholino) propanesulphonic acid, $8 \mathrm{mM}$ sodium acetate, 1 mM EDTA), blotted onto Hybond-N (Amersham International, Amersham, Bucks, UK) nylon filters using $20 \times$ SSC as a transfer buffer overnight ( $1 \times \mathrm{SSC}$ is $0.3 \mathrm{M} \mathrm{NaCl}$ and $0.3 \mathrm{M}$ trisodium citrate), and the RNA was bound and cross-linked using UV radiation (StratalinkerStratagene Ltd.). C-myc mRNA was detected using a riboprobe from a linearized human c-myc fragment D414-433 (31) and signals were normalized against a random primed (Amersham Int.) rat GAPDH cDNA 
probe. Filters were prehybridized in $6 \times$ SSC, $5 \times$ Denhardt's solution, $5 \mu \mathrm{g} / \mathrm{ml}$ denatured salmon sperm DNA (Sigma), $0.2 \%$ SDS, and $50 \%$ formamide. Prehybridization was performed at $65^{\circ} \mathrm{C}$ (c-myc riboprobe) or $42^{\circ} \mathrm{C}$ (GAPDH probe) for $1 \mathrm{~h}$ and hybridization for $16 \mathrm{~h}$ at the above temperatures. The filters were then washed with $6 \times$ SSC, $0.1 \%$ SDS and $2 \times \mathrm{SSC}, 0.1 \%$ SDS at $58^{\circ} \mathrm{C}$, and exposed using a Cronex intensifying screen (DuPont Co.) and Kodak-X-omatic AR film at $-70^{\circ} \mathrm{C}$ overnight. For repeat hybridizations, the filters were stripped by boiling in $0.1 \%$ SDS for $1 \mathrm{~h}$ and exposing overnight to verify loss of signal. Scanning densitometry was used to determine changes in mRNA levels.

Immunocytochemical analysis of $c-M y c$ protein. VSMCs were plated onto eight-well Tissue-Tek chamber slides (LabTek Ltd.) and cultured for $48 \mathrm{~h}$ in DME containing $10 \%$ FCS. The medium was then replaced with DME $+10 \%$ FCS alone or with $30 \mu \mathrm{g} / \mathrm{ml}$ of sense c-myc, antisense c-myc, 2-bp mismatch antisense c-myc, antisense $\alpha$-sm-actin, or antisense GAPDH oligodeoxynucleotides. Cells were fixed and processed after $24 \mathrm{~h}$ using an affinity-purified pan-myc antibody as described before (32). Slides were viewed immediately after preparation on a model MRC500 confocal microscope (Bio-Rad Laboratories) using Nimbus image analysis software (Research Systems) to quantify relative c-Myc protein fluorescence objectively. Each experiment was repeated three times and image formation, collection, and quantification were performed using the same objective lens aperture, machine gain, and blackness settings with a Kalman filter averaging the image characteristics over 30 image scans. 40 cells per treatment group, selected randomly by computer generation of field coordinates, were analyzed in two separate subconfluent fields of cells. The observer was blinded to the treatment groups. Average intensity of fluorescence was quantified by the computer for each nucleus, and the mean intensity of 40 nuclei used for data comparison. A similar process was used to assess cytoplasmic background staining for each cell and these figures were subtracted from the nuclear signal to yield a net nuclear signal expressed as the percentage of the signal from control cells.

ELISA. c-Myc protein levels in cells were determined using an ELISA, as previously described (28). Briefly, protein lysates were obtained from cells proliferating in media containing $10 \%$ FCS, treated with each antisense oligodeoxynucleotide for $24 \mathrm{~h}$ at $30 \mu \mathrm{g} / \mathrm{ml} .2 \times 10^{6}$ cells were lysed in RIPA buffer ( $50 \mathrm{mM} \mathrm{NaCl}, 25 \mathrm{mM}$ Tris [ $\mathrm{pH} 8.2$ ], $0.5 \%$ NP40, $0.5 \%$ sodium deoxycholate, $0.1 \%$ SDS, $0.1 \%$ sodium azide, $1 \%$ bovine serum albumin, $0.2 \%$ aprotinin, $0.5 \mathrm{mM}$ PMSF, $1 \mathrm{mM}$ DTT, $10 \mathrm{mM}$ iodoacetamide). Lysates were analyzed in duplicate using affinity-purified polyclonal pan-myc antibody as capture antibody and the monoclonal anti-c-Myc antibody MYC1-3C7 conjugated to alkaline phosphatase as detection antibody (28). Signals were developed using the AMPAK (Dako Corp., Santa Barbara, CA) cyclic substrate system. The absolute mean number of $\mathrm{c}-\mathrm{Myc}$ protein molecules per cell was determined by comparison with a bacterially expressed c-Myc protein standard, assuming a molecular mass for c-Myc protein of $50 \mathrm{kD}$.

Statistical analysis. Statistical analysis was performed using Student's $t$ test to evaluate differences in cell numbers, fluorescence signals, and neointimal areas.

\section{Results}

Effect of antisense c-myc oligodeoxynucleotides on cell proliferation. We first investigated the effect of antisense oligodeoxynucleotides on the proliferation of VSMCs. 15-bp oligonucleotides were synthesized corresponding to part of the human c$m y c$ sense sequence, the corresponding human antisense c-myc sequence, a 2-bp internal mismatch of antisense human c- $m y c$, and antisense sequences to $\alpha$-sm-actin and GAPDH. This sequence of human antisense c-myc differs from the rat sequence by one base at the $5^{\prime}$ end. However, preliminary experiments showed that both human and rat specific 15-mer antisense c- $m y c$ sequences suppress rat c-myc expression to a similar extent. As the retrovirally infected VSMCs used as a control contain a human sequence, the human 15-mer antisense c-myc sequence was used for all other experiments.

Cell proliferation in response to incubation with each oligonucleotide was monitored by cell counting. Quiescent rat VSMCs stimulated with serum (control cells) exhibited loga-
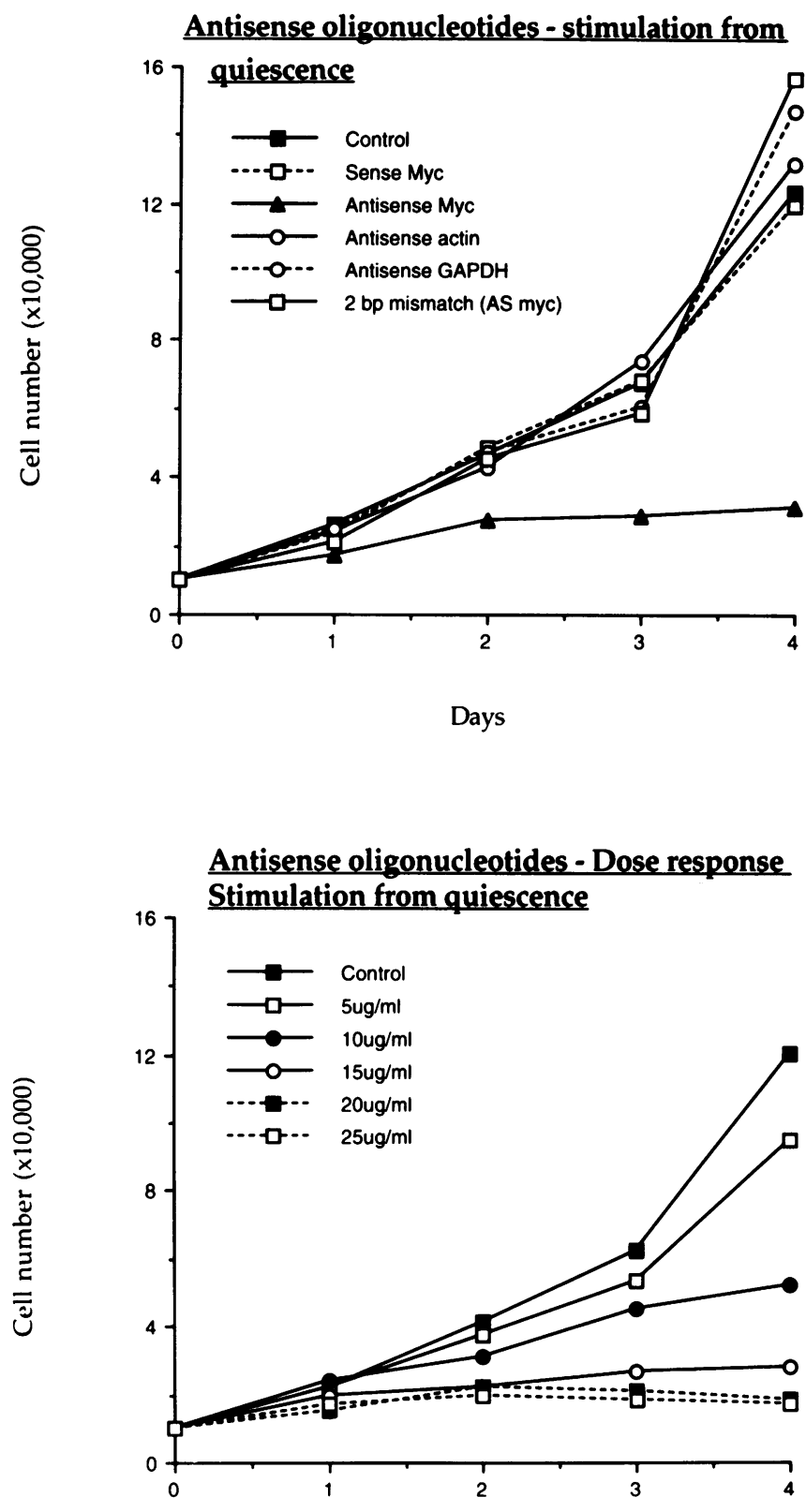

Days

Figure 1. Effect of antisense c-myc oligodeoxynucleotide on mitogenic stimulation of quiescent VSMCs. The upper panel shows cells treated with normal culture medium alone (control cells) or with $30 \mu \mathrm{g} / \mathrm{ml}$ of sense c-myc, antisense c-myc, a 2-bp internal mismatch antisense c-myc, antisense $\alpha$-sm-actin, and antisense GAPDH oligodeoxynucleotides. A significant difference was observed $(P<0.05)$ between antisense c-myc-treated VSMCs and controls from day 2 onwards. The lower panel shows the effect of antisense c-myc oligodeoxynucleotides at various concentrations on serum-stimulated quiescent VSMCs or cells cultured without oligodeoxynucleotides (control cells). 

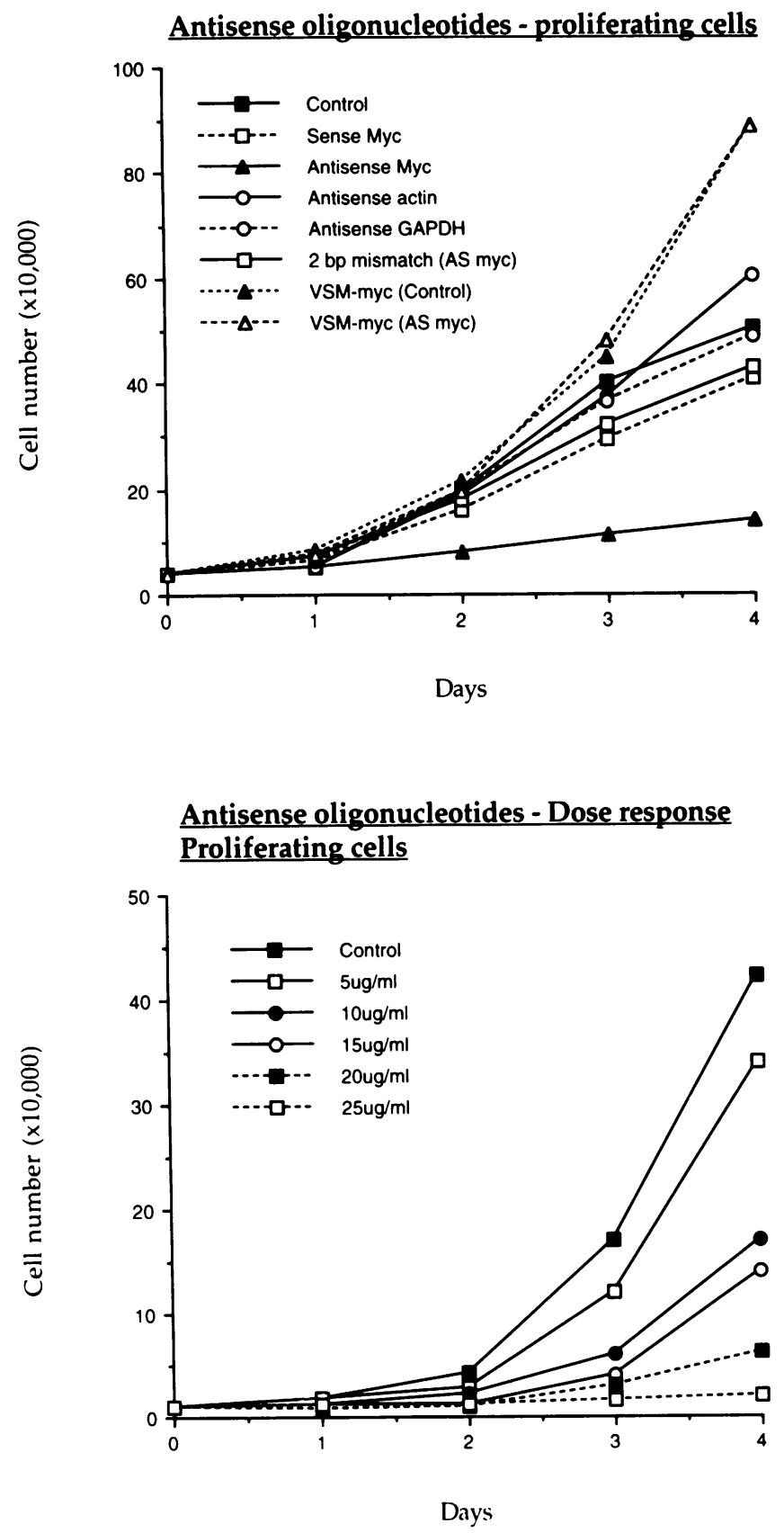

Figure 2. Effect of antisense c-myc oligodeoxynucleotide on proliferation of exponentially proliferating VSMCs and VSM-myc cells. The upper panel shows normal VSMCs and VSMCs constitutively expressing c-myc (VSM-myc cells) treated with normal culture medium alone (control cells) or with $30 \mu \mathrm{g} / \mathrm{ml}$ of sense c-myc, antisense c-myc, a 2-bp internal mismatch antisense c-myc, antisense $\alpha$-sm-actin, and antisense GAPDH oligodeoxynucleotides. VSM-myc cells were treated with normal culture medium alone (VSM-myc control) or with $30 \mu \mathrm{g} / \mathrm{ml}$ of antisense c-myc oligodeoxynucleotides (VSM-myc AS myc). A significant difference $(P<0.05)$ was observed between antisense c-myc-treated normal VSMCs and control cells, but no difference between VSM-myc control cells or VSM-myc cells treated with antisense c-myc (VSM-myc AS myc). The lower panel shows the effect of antisense c-myc oligodeoxynucleotides at various concentrations on exponentially proliferating normal VSMCs or cells cultured without oligodeoxynucleotides (control cells).

rithmic growth by $\sim 48 \mathrm{~h}$ after serum addition (Fig. 1). In contrast, incubation of quiescent VSMCs with antisense c-myc oligodeoxynucleotides during mitogenic stimulation resulted in significant reduction in increase in live cell number from day 2 onwards ( $P<0.05$ versus control cells) and the extent of inhibition was proportional to the concentration of antisense oligodeoxynucleotides present (Fig. 1). No significant inhibition of proliferation was observed in cells incubated with sense c-myc, a 2-bp internal mismatch antisense c- $m y c$, antisense $\alpha$-sm-actin, or antisense GAPDH oligodeoxynucleotides.

Significant reduction of proliferation $(P<0.05)$ from day 2 onwards was also observed in exponentially proliferating VSMCs after antisense c-myc oligodeoxynucleotide treatment (Fig. 2). Inhibition of proliferation was also proportional to concentration of the antisense c-myc oligodeoxynucleotide (Fig. 2). 50\% inhibition of proliferation $\left(\mathrm{IC}_{50}\right)$ occurs at an oligodeoxynucleotide concentration of $10 \mu \mathrm{g} / \mathrm{ml}$ and proliferation is effectively completely blocked at a concentration of 30 $\mu \mathrm{g} / \mathrm{ml}$. Inhibition of proliferation by antisense c-myc was confirmed flow cytometrically. This was evident as a marked reduction in the proportion of cells in S-phase with accumulation of cells in $G_{0} / G_{1}$ (data not shown). None of the control oligodeoxynucleotides had any detectable effect on growth of exponentially proliferating VSMCs.

To determine whether the antiproliferative effect of antisense c- $m y c$ oligodeoxynucleotides on VSMCs is specifically due to suppression of $c-m y c$ expression, we examined the effects of c-myc antisense oligodeoxynucleotides on the growth of a clone of rat VSMCs that constitutively expresses high levels of an exogenous c- $m y c$ gene under the control of a retroviral

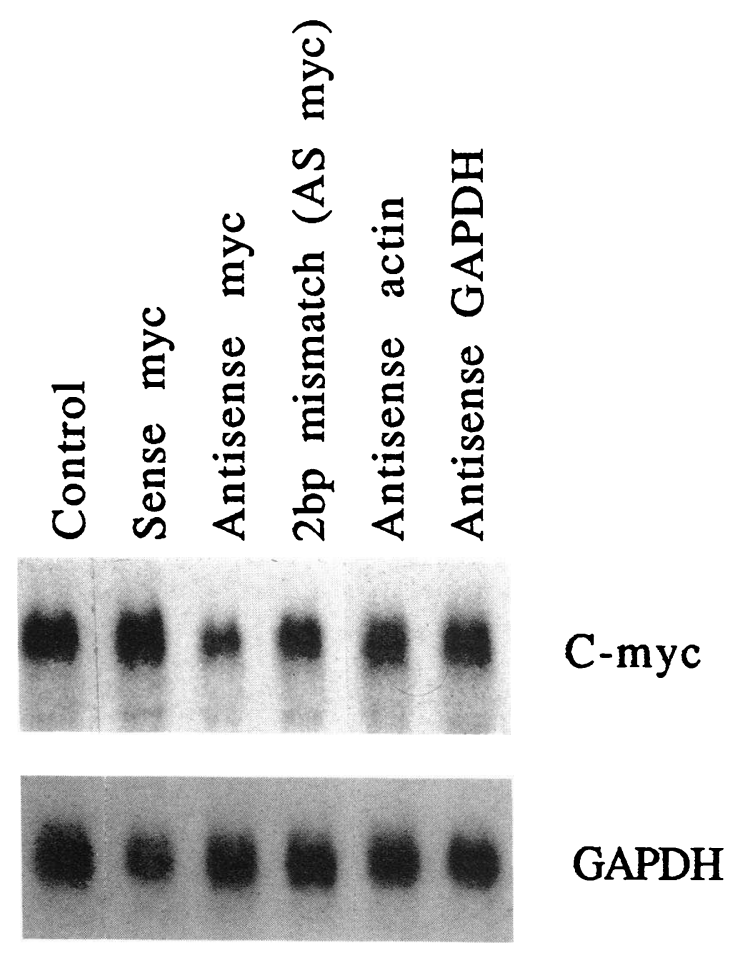

Figure 3. Effect of antisense c-myc oligodeoxynucleotides on c-myc mRNA expression. RNA was extracted from VSMCs after incubation with medium alone (control cells) or with $30 \mu \mathrm{g} / \mathrm{ml}$ of sense c-myc, antisense c-myc, a 2-bp internal mismatch antisense c-myc, antisense $\alpha$-sm-actin, and antisense GAPDH oligodeoxynucleotides for $24 \mathrm{~h}$ (all oligodeoxynucleotides at $30 \mu \mathrm{g} / \mathrm{ml}$ ). RNAs were fractionated on an agarose gel and c-myc expression determined by Northern blotting analysis. A reduction in the antisense c-myc-treated group of $\sim 50 \%$ is evident, as assessed by scanning densitometry. Equal loading of total RNA was ensured by prior spectrophotometric quantification of RNA and subsequent reprobing for GAPDH. 


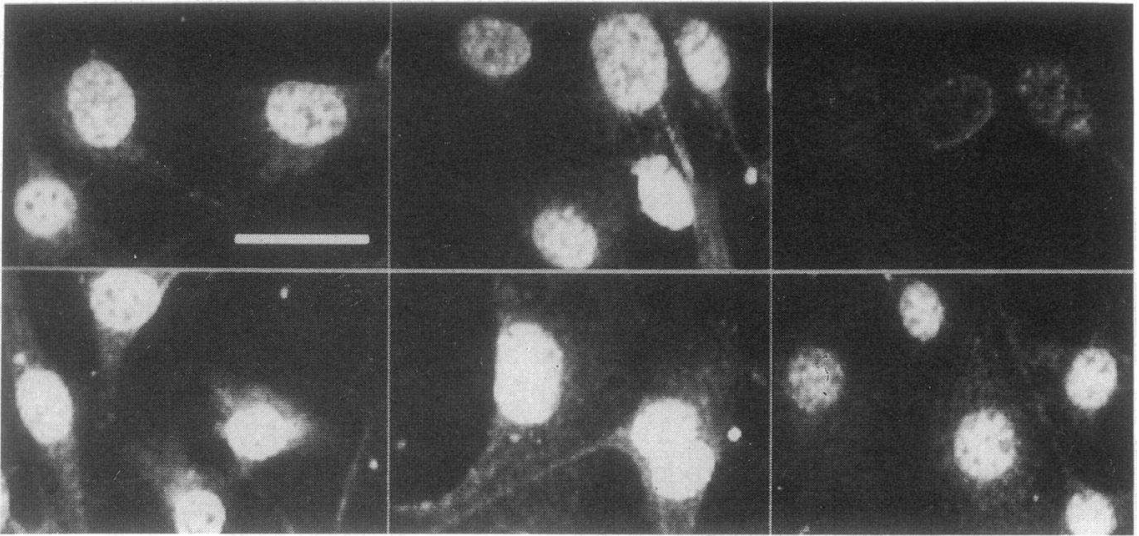

Antisense actin
Antisense GAPDH
2 bp mismatch antisense myc

B

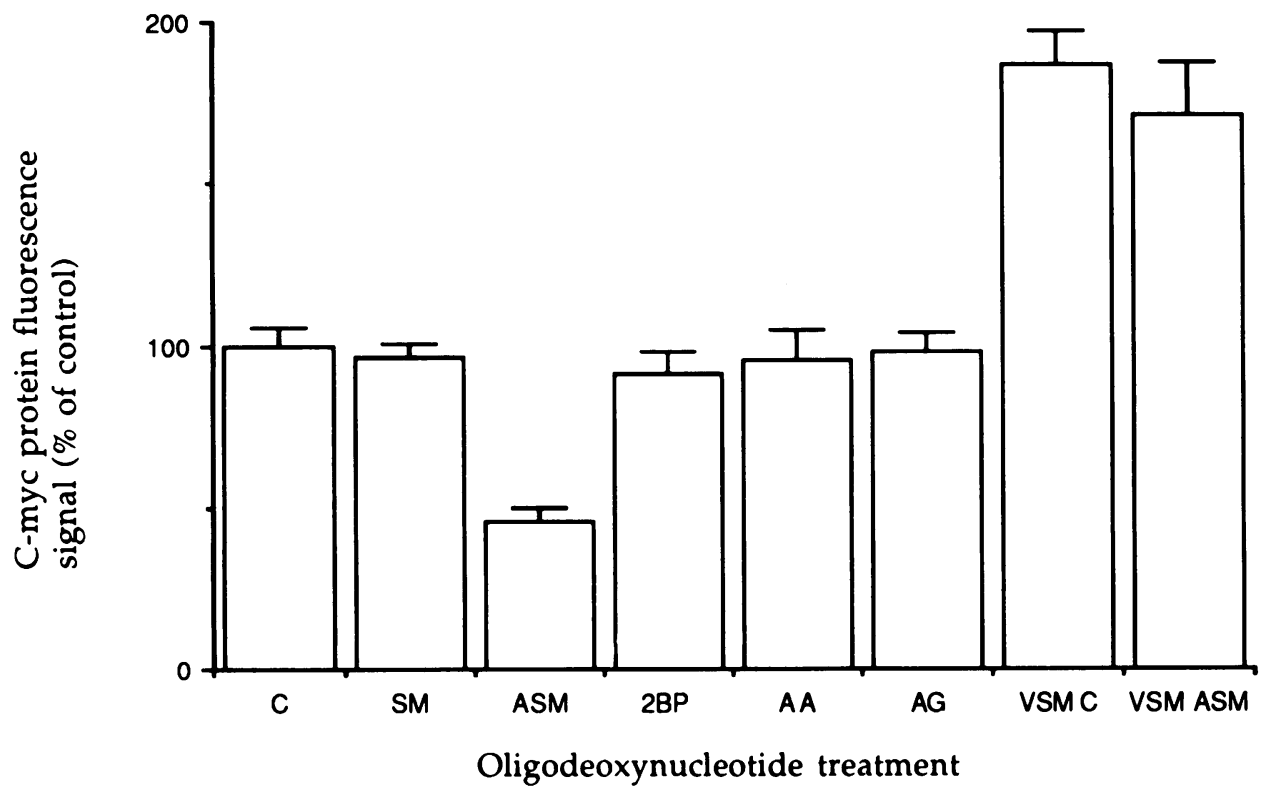

Figure 4. Immunofluorescence quantitation of $\mathrm{c}-\mathrm{Myc}$ protein levels in VSMCs after treatment with antisense cmyc oligodeoxynucleotide. $(A)$ Indirect immunofluorescence of c-Myc protein of normal VSMCs cultured in medium alone (control cells) or with $30 \mu \mathrm{g} / \mathrm{ml}$ of sense $c-m y c$, antisense c-myc, a 2 bp internal mismatch antisense c- $m y c$, antisense $\alpha$-smactin, and antisense GAPDH oligodeoxynucleotides for 24 $\mathrm{h}$ (all oligodeoxynucleotides were used at $30 \mu \mathrm{g} / \mathrm{ml})$. (B) Histogram of c-Myc protein immunofluorescence intensity $24 \mathrm{~h}$ after each treatment. Abbreviations: $\mathrm{C}$, control cells; SM, sense c-myc; ASM, antisense c-myc; 2 bp, 2-bp internal mismatch antisense c-myc; AA, antisense $\alpha$-actin; $A G$, antisense GAPDH. Histogram also shows fluorescence signals from VSM-myc cells treated without oligodeoxynucleotides $(V S M C)$ or with antisense c-myc oligodeoxynucleotides ( $V S M$ $A S M)$. Nuclear fluorescence signals were quantified in 40 cells per group using image analysis software, and the means are expressed as the percentage of the mean signal obtained in control cells. Error bars represent SEMs. promoter (VSM-myc cells). Due to their high levels of c-myc expression, VSM-myc cells would be expected to be substantially refractory to the effects of antisense c-myc oligodeoxynucleotides. We observed no significant inhibition of proliferation in VSM-myc cells after treatment with antisense c-myc oligodeoxynucleotides at concentrations that induced complete growth arrest in normal VSMCs (Fig. 2). Flow cytometry of VSM-myc cells confirmed no change in S-phase populations after treatment with antisense c- $m y c$ oligodeoxynucleotides $(30 \mu \mathrm{g} / \mathrm{ml})$ (data not shown).

Effect of antisense c-myc oligodeoxynucleotides on expression of c-myc in cultured vascular smooth muscle cells. To investigate whether the inhibitory effects of c-myc antisense oligodeoxynucleotides on cell proliferation were related to inhibition of c-myc expression, we measured both c-myc mRNA and protein in proliferating VSMCs treated with antisense oligodeoxynucleotides. At concentrations that effectively inhibit proliferation of exponentially growing VSMCs, antisense c$m y c$ oligodeoxynucleotides significantly reduced the expression of both c-myc mRNA (Fig. 3) and protein (Fig. 4). Scanning densitometry showed that average c-myc mRNA level was reduced by $\sim 50 \%$ after $24 \mathrm{~h}$ incubation with antisense c-myc oligodeoxynucleotides. C-Myc protein levels in cells were examined by quantitative immunofluorescence and showed a $55 \%( \pm 5 \%)$ reduction after $24 \mathrm{~h}$ incubation in antisense c-myc oligodeoxynucleotides. The reduction in c-Myc immunofluorescence occurs in each cell, with a $<10 \%$ variability between cells (Fig. 4). The observed reduction in VSMC c-Myc protein levels was confirmed in bulk populations of cells by ELISA ( Table I). In contrast to the effects of the antisense c-myc oligodeoxynucleotides, we observed no significant reduction in c$m y c$ mRNA levels after incubation with sense c-myc, the 2-bp internal mismatch antisense c- $m y c, \alpha$-sm-actin or antisense GAPDH control oligodeoxynucleotides (Fig. 3). Levels of c- 
Table I. C-Myc Protein Levels in Molecules per Cell for Normal VSMCs and VSM-myc Cells after Culture in Media Containing Oligonucleotides for $24 \mathrm{~h}$

\begin{tabular}{lc}
\hline \multicolumn{1}{c}{ Treatment } & C-Myc protein \\
\hline & molecules/cell \\
Control & $3,700(350)$ \\
Sense c-myc & $3,600(450)$ \\
Antisense c-myc & $1,650(300)^{*}$ \\
2-bp mismatch antisense c-myc & $3,200(250)$ \\
Antisense $\alpha$-sm-actin & $4,150(350)$ \\
Antisense GAPDH & $3,950(400)$ \\
VSM-myc cells: control & $27,150(1500)$ \\
VSM-myc cells: antisense c- $m y c$ treated & $25,800(1650)$
\end{tabular}

Cells were cultured in medium $+10 \%$ FCS alone for $48 \mathrm{~h}$ to obtain exponential growth and then oligodeoxynucleotides added. Values are means $(\mathrm{SEM}) .{ }^{*} P<0.05$.

Myc protein in VSMCs were similarly unaffected by these control oligodeoxynucleotides, as determined by immunofluorescence (Fig. 4) and ELISA (Table I). VSM-myc cells, expressing high levels of $\mathrm{c}-\mathrm{Myc}$ protein, showed no change in c-Myc protein levels after treatment with antisense c-myc oligodeoxynucleotides (Fig. 4 B and Table I).

Expression of c-myc in arteries after balloon injury. We examined the induction of c-myc in rat carotid arteries after injury with a balloon catheter. RNA was extracted from injured and uninjured arteries at various times, fractionated on agarose gels, and probed for c-myc expression. After balloon arterial injury of the left carotid artery we observed a characteristic temporal sequence of c-myc mRNA induction. Little detectable c-myc mRNA was evident at time 0 . Injury caused the rapid induction of $c-m y c$ mRNA which peaks after $2 \mathrm{~h}$ and which was still detectable, albeit at a lower level, after $4 \mathrm{~h}$ (Fig. 5 ). No such induction of c-myc was detected in the uninjured right carotid arteries. The application of antisense c- $m y c$ oligodeoxynucleotides to the adventitial surface of the arterial wall reduces the 2-h c-myc mRNA peak by $\sim 75 \%$ (Fig. 5 ). No such reduction in c-myc mRNA was observed after application of sense c-myc oligodeoxynucleotides (Fig. 5).

Effect of antisense c-myc oligodeoxynucleotides on arterial neointima formation. We next examined the effect on arterial neointimal formation of application of antisense c-myc oligodeoxynucleotides to the adventitial surface of the arterial wall immediately after balloon catheter injury. Neointimal areas were assessed in the distal treated segments and proximal untreated segments of the arteries $14 \mathrm{~d}$ after injury (Fig. 6 and 7). Application of antisense c-myc oligodeoxynucleotide significantly reduced neointimal formation following balloon injury $(P<0.05)$ when compared with either sense c-myc oligodeoxynucleotide or application of gel alone (Fig. 6 and 7). The reduction in neointimal area was localized to the areas to which the gel containing antisense c-myc oligodeoxynucleotides had been applied: proximal sections of the artery showed similar neointimal areas in all groups (Figs. 6 and 7). Some degree of variability was observed in the amount of neointima present in the antisense c-myc-treated group. Four out of nine arteries exhibited virtually no neointima formation in the antisense c-myc-treated segments, despite a markedly thickened intima in the proximal, untreated segment of the same vessel (Figs. 6 $B$ and 7).

\section{Discussion}

Antisense oligodeoxynucleotides complementary to sequences in specific genes are useful probes for examining the requirement for expression those genes in various biological processes. Antisense strategies have been successfully used to investigate single gene function in VSMC proliferation (10-13, 25, 26). We demonstrate here that antisense oligodeoxynucleotides complementary to sequences in the c-myc proto-oncogene suppress in vitro, in a dose-dependent fashion, the proliferation of VSMCs stimulated by mitogens from quiescence and also exponential proliferation of VSMCs already in the cell cycle. At an antisense oligodeoxynucleotide concentration of $30 \mu \mathrm{g} / \mathrm{ml}$, inhibition of proliferation is almost complete. The inhibitory effect of antisense c-myc oligodeoxynucleotides on proliferation of serum-stimulated quiescent VSMCs and exponentially proliferating VSMCs implies that c-myc expression is required both for VSMCs to enter the cell cycle and also for continuous proliferation.

Concentrations of c-myc antisense oligodeoxynucleotides that significantly inhibit cell proliferation suppress c-myc mRNA and protein to $\sim 45-50 \%$ of the normal levels in proliferating cells. Although incomplete, this suppression of c-myc expression appears sufficient to inhibit VSMC proliferation and is consistent with a previous analogous study in HL60 promyelocytic leukaemia cells (20). In contrast to an earlier study on VSMCs (26) we have observed no significant growth stimulatory effect from low-dose antisense c-mycoligodeoxynucleotides. The inhibition of proliferation we observe appears to be a sequence-specific effect of antisense c-myc oligodeoxynucleotides because no growth inhibition or suppression of expression of c-myc mRNA and c-Myc protein was observed after incubation of VSMCs with a sense c-myc oligodeoxynucleotide, a 2-bp mismatch antisense c-myc oligodeoxynucleotide, or oligodeoxynucleotides complementary to sequences in genes for $\alpha$-sm-actin or GAPDH. It is interesting to note that antisense GAPDH oligodeoxynucleotides had no observable effect on GAPDH message levels; nor indeed did antisense $\alpha$ sm-actin affect corresponding $\alpha$-sm-actin mRNA levels (data not shown). We suggest that this is due to the relatively high

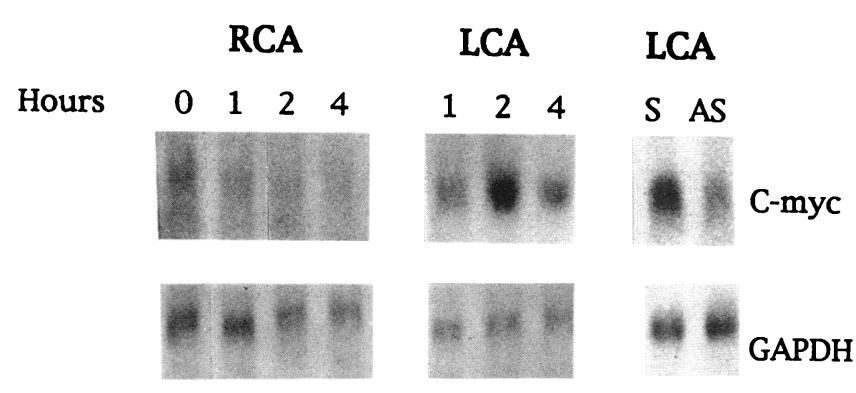

Figure 5. Northern blotting hybridisation analysis of c-myc mRNA expression in whole carotid arteries after balloon injury. Following injury to the left carotid artery ( $L C A)$, RNA was isolated at 1,2 , and $4 \mathrm{~h}$ from both the injured left and the uninjured right carotid arteries $(R C A)$. A low baseline level of c-myc expression was observed in uninjured arteries but this did not vary over time. In contrast, rapid induction of c-myc mRNA occurred in the injured left artery. This induction is maximal at around $2 \mathrm{~h}$ after injury and is $\sim 75 \%$ reduced by treatment with antisense c-myc $(A S)$ oligodeoxynucleotides $(200$ $\mu \mathrm{g})$ immediately after injury but not by sense c-myc $(S)$ sequences. Equal RNA loading was confirmed by reprobing the filter for GAPDH expression. 


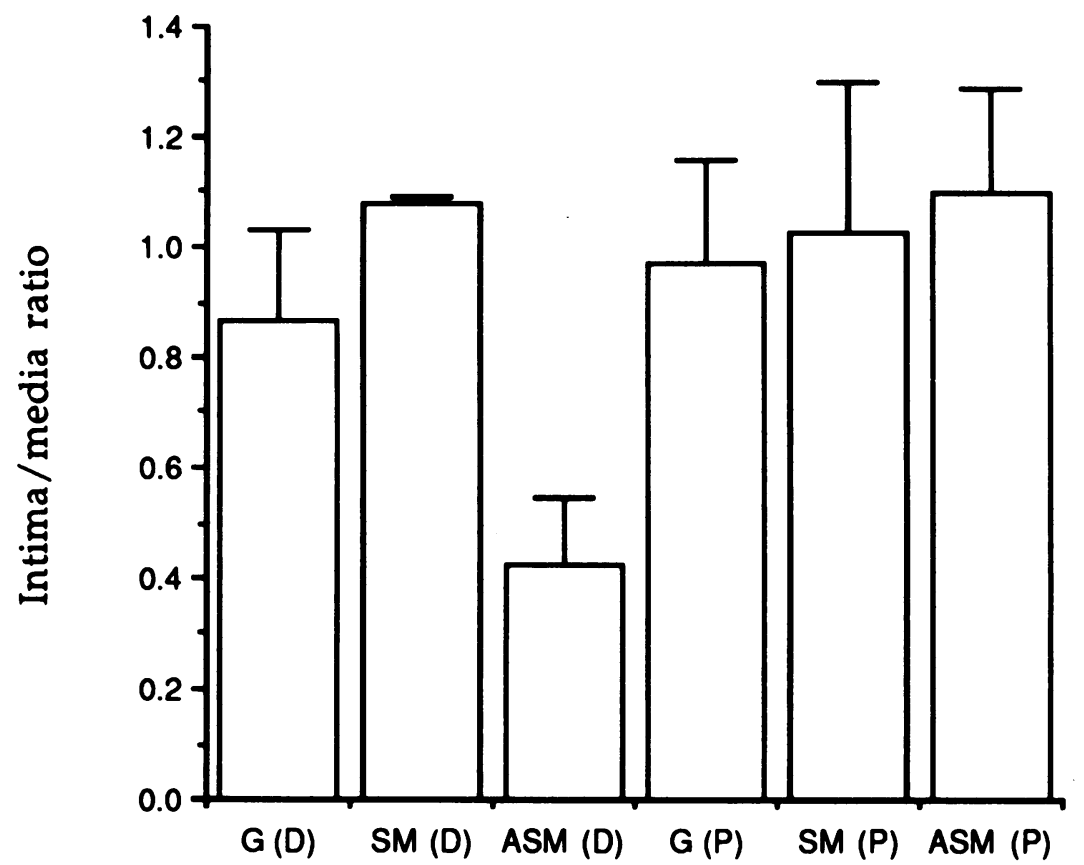

\section{Oligodoeoxynucleotide treatment}

B

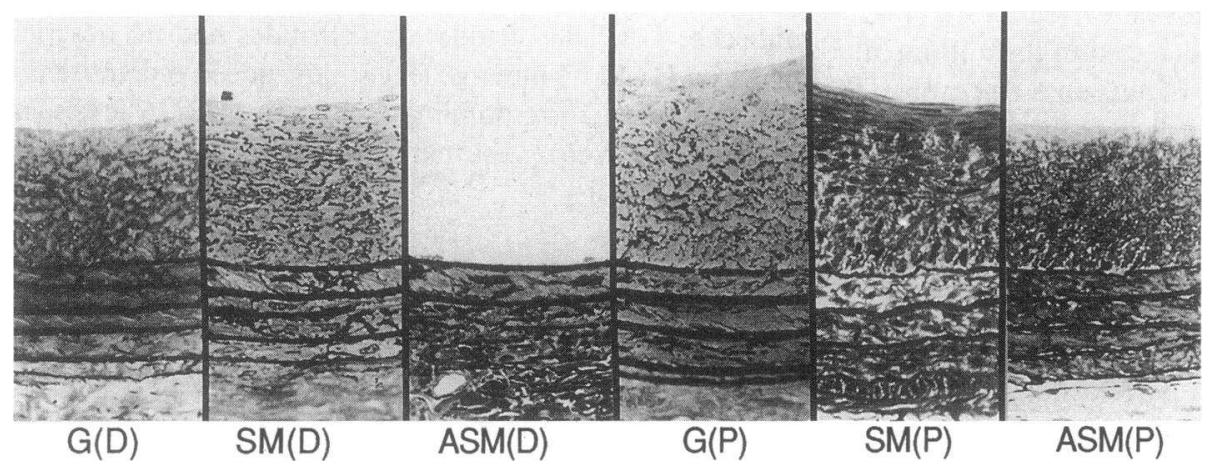

Figure 6. Inhibition of neointima formation by antisense c-myc oligodeoxynucleotide. $(A)$ Histogram of the intima to media ratios of distal $(D)$ (injured and treated) and proximal $(P)$ (injured but untreated) arterial segments after treatment with pluronic gel alone $(G)$, sense $c-m y c(S M)$ and antisense c-myc $(A S M)$ oligodeoxynucleotides. After injury, oligodeoxynucleotides ( 200 $\mu \mathrm{g}$ ) in $0.25 \%$ pluronic gel were applied to the distal third of the artery and vessels were examined morphometrically after $14 \mathrm{~d}$. A significant difference between antisense $c-m y c$ and both sense c-myc and gel alone groups $(P<0.05)$ was observed for the distal (treated) segments. Error bars represent SEMs. (B) Sections of the arterial wall for distal $(D)$ (treated) and proximal $(P)$ (untreated) arterial segments showing reduction in neointimal area aftertreatment with antisense c-myc oligodeoxynucleotides in the distal part of the artery. levels of these message species compared with c-myc. Antisense c-myc suppresses c-myc mRNA in a concentration-dependent manner and does not suppress $c-m y c$ when high mRNA levels are expressed, as in VSM-myc cells. We therefore feel it is likely that the concentrations of antisense GAPDH and $\alpha$-sm-actin oligodeoxynucleotides used were insufficient to suppress their cognate mRNA levels.

The mechanism by which antisense oligodeoxynucleotides inhibit expression of target genes within cells is incompletely understood but is thought to involve interference with translation of the target mRNA and/or induction of cleavage of DNA/mRNA hybrids by RNAase $\mathrm{H}$ ( see reference 33 for review). A further possibility is that the mere presence of intra- cellular DNA/RNA hybrids may induce the production of endogenous antiproliferative cytokines, for example interferon. This latter mechanism is, however, an unlikely explanation for the growth inhibition we observe in VSMCs by antisense c-myc oligodeoxynucleotides since antisense oligodeoxynucleotides complementary to other genes expressed in VSMCs exert no inhibitory effect on VSMC growth. A more general question as to the mode and specificity of action of antisense oligodeoxynucleotides arises from the observation that oligodeoxynucleotides as short as 13 bases can sometimes induce nonspecific degradation of mRNAs (34). Any effects of antisense deoxynucleotides might therefore be due to degradation of nontargeted mRNAs. To try to eliminate this possibility, and to confirm the 

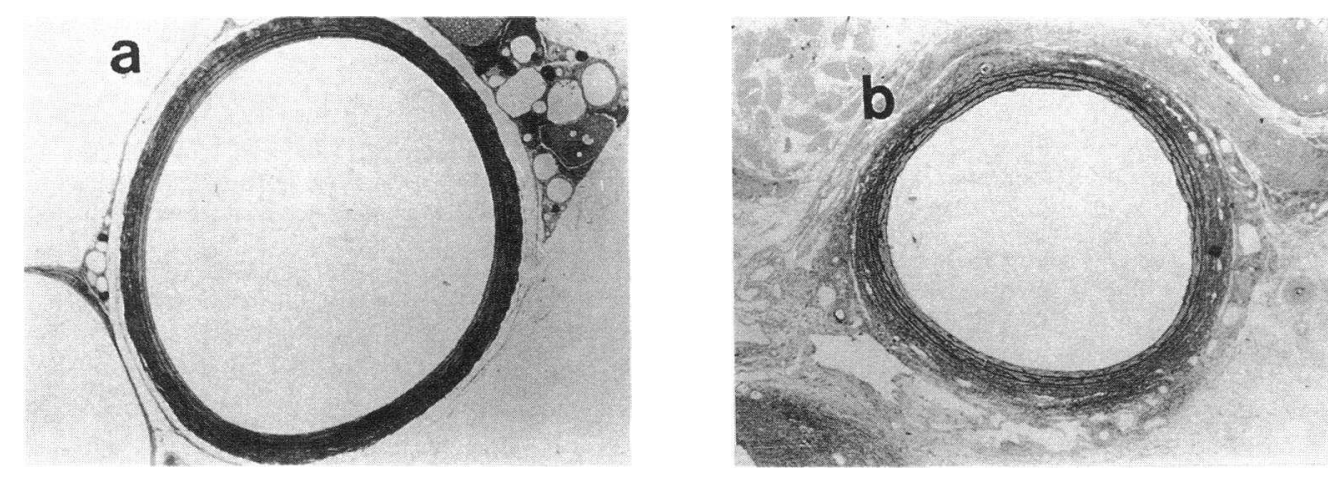

Figure 7. Microscopic analysis of artery walls following injury. Sections of the arterial wall of (a) normal, uninjured right carotid artery, $(b)$ antisense c$m y c$-treated distal segment of the left carotid artery (LCA), (c) pluronic gel alone treated distal LCA, $(d)$ antisense c-myc proximal LCA (oligodeoxynucleotide applied only to distal segment). Arrows indicate thickness of neointima. There is a marked reduction in the
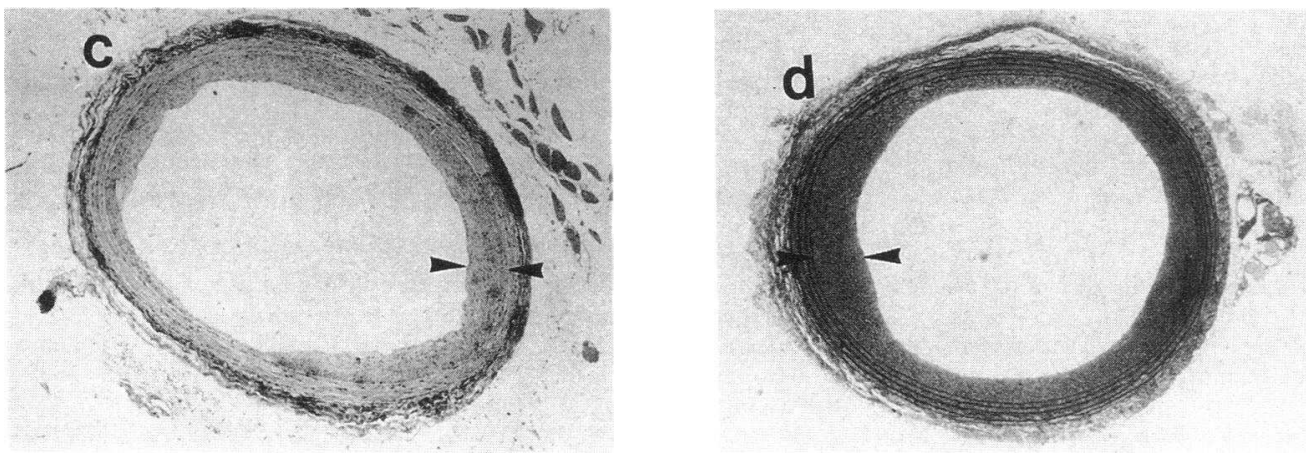
neointimal area in the distal segment of the artery treated with antisense c-myc. Proximal sections of the antisense-treated arteries (which did not receive oligodeoxynucleotide application ) show similar neointimal areas to arteries treated with pluronic gel alone, indicating that the inhibition of neointimal formation is restricted to the site of application of the antisense c-myc oligodeoxynucleotide.

specificity of action of the c-myc antisense oligodeoxynucleotide in our system, we asked whether the inhibition of cell proliferation mediated by antisense c-myc oligodeoxynucleotides is overcome by elevated expression of exogenous c-myc. We found that VSMCs that overexpress c-myc from an exogenous retrovirus promoter (VSM-myc cells) are not growth inhibited by concentrations of antisense c-myc oligodeoxynucleotides that induce almost complete growth arrest in normal VSMCs, nor are their intracellular levels of c-Myc protein significantly suppressed. This is consistent with the notion that elevated c-myc mRNA can titrate out the growth-inhibitory effect of antisense c-myc oligodeoxynucleotide and suggests that antisense c- $m y c$ oligodeoxynucleotides block VSMC proliferation by sequence-specific interaction with c-myc mRNA. Nonetheless, it remains possible that antisense oligodeoxynucleotides work by some alternative mechanism that does not involve sequestration and degradation of $c-m y c$ mRNA, for example by direct interaction with some intracellular protein. Presumably, such an interaction would also be competitively titrated by overexpression of $\mathrm{c}-m y c$.

Following balloon catheter injury, c-myc expression is rapidly induced in the arterial wall, with the peak of expression at 2 $\mathrm{h}$ (as shown here and in references 35 and 36). This peak expression is significantly suppressed by the application of antisense c-myc oligodeoxynucleotides to the adventitial surface of the arterial wall, arguing that the oligodeoxynucleotide penetrates the adventitia and acts to suppress c-myc expression in VSMCs in the media within $2 \mathrm{~h}$. The effect of oligodeoxynucleotide application is not, however, limited to the short term since it leads to marked reduction in neointima formation some $14 \mathrm{~d}$ later. As the applied oligodeoxynucleotide is unlikely to persist for very long in vivo, we suggest that the protracted process of neointima formation is critically dependent upon mitogenic events that occur very shortly after injury. Presumably, antisense c-myc oligodeoxynucleotides block entry of
VSMCs into the cell cycle and suppress proliferation of those VSMCs already in cycle. Alternatively, it is possible that the antisense c-myc oligodeoxynucleotide interferes with VSMC migration, a process that also contributes to the neointimal lesion (29). Indeed, antisense c-myc oligodeoxynucleotides have been shown to reduce VSMC migration in vitro, and at somewhat lower doses than those required to reduce proliferation (26). Our data complement and extend the previous study of Simons et al. (13) which demonstrated inhibition of VSMC accumulation in arteries in vivo using antisense oligodeoxynucleotides to block expression of the proto-oncogene c- $m y b$.

Although the reduction in neointimal area after injury demonstrates the potential for the use of antisense strategies to modulate c-myc expression after angioplasty, further studies are needed to establish whether the suppression of neointima formation is maintained, to determine the minimum effective dose required for neointima suppression and to investigate whether the inhibitory effect is primarily on VSMC proliferation or VSMC migration. Furthermore, in addition to VSMCs, arterial walls contain a variety of cell types that may also be implicated in the neointimal process. Although no effect was observed on medial thickness or wound healing, it will be necessary to examine the relative uptake and effects of antisense oligodeoxynucleotides on each cell type. For example, c-myc expression is likely to be induced in endothelial cells after injury. Antisense c-myc oligodeoxynucleotides may thus suppress endothelial cell division and/or migration which would reduce reendothelialization and could complicate arterial repair. Studies designed to address the above issues are presently underway.

In conclusion, we have demonstrated that antisense oligodeoxynucleotides can be used to suppress c-myc expression in VSMCs both in vitro and in vivo and thereby inhibit VSMC proliferation and formation of neointima after arterial injury. $\mathrm{C}-m y c$ is thus an essential component of VSMC proliferation 
and appears to be an excellent target for potential therapies designed to prevent angioplasty restenosis and its associated pathologies.

\section{Acknowledgments}

This study was supported by a British Heart Foundation Clinical Scientist Fellowship to Dr. Bennett and by a British Heart Foundation Grant to Dr. McEwan.

\section{References}

1. McBride, W., R. Lange, and L. Hillis. 1988. Restenosis after successful coronary angioplasty: Pathophysiology and prevention. N. Engl. J. Med. 318:1734-1737.

2. Austin, G. E., N. B. Ratliff, J. Hollman, S. Tabei, and D. F. Phillips. 1985. Intimal proliferation of smooth muscle cells as an explanation for recurrent coronary artery stenosis after percutaneous transluminal coronary angioplasty. J. Am. Coll. Cardiol. 6:369-375.

3. Clowes, A. W., and M. J. Karnowsky. 1979. Suppression by heparin of smooth muscle proliferation in injured arteries. Nature (Lond.). 265:625-627.

4. Guyton, J. R., R. D. Rosenberg, A. W. Clowes, and M. J. Karnovsky. 1980. Inhibition of rat arterial smooth muscle cell proliferation by heparin. In vivo studies with anticoagulant and non anticoagulant heparin. Circ. Res. 46:625634.

5. Clowes, A. W., and M. M. Clowes. 1985. Kinetics of cellular proliferation after arterial injury. II. Inhibition of smooth muscle growth by heparin. Lab. Invest. 52:611-616.

6. Powell, J. S., R. K. Muller, M. Rouge, H. Kuhn, F. Hefti, and H. R. Baumgartner. 1990. The proliferative response to vascular injury is suppressed by angiotensin-converting enzyme inhibition. J. Cardiovasc. Pharmacol. 16:S42. (Abstr.)

7. Powell, J. S., J. P. Clozel, R. K. Muller, H. Kuhn, F. Hefti, M. Hosang, and H. R. Baumgartner. 1989. Inhibitors of angiotensin-converting enzyme prevent myointimal proliferation after vascular injury. Science (Wash. DC). 245:186188.

8. Hansson, G. K., and J. Holm. 1991. Interferon- $\gamma$ inhibits arterial response to injury. Circulation. 84:1266-1272.

9. Schwartz, R., D. Holmes and E. Topol. 1992. The restenosis paradigm revisited: An alternative proposal for cellular mechanisms. J. Am. Coll. Cardiol. 20:1284-1293.

10. Simons, M., and R. D. Rosenberg. 1992. Antisense non muscle myosin heavy chain and c-myb oligodeoxynucleotides suppress smooth muscle cell proliferation in vitro. Circ. Res. 70:835-843.

11. Speir, E., and S. E. Epstein. 1992. Inhibition of smooth muscle proliferation by an antisense oligodeoxynucleotide targeting the messenger RNA encoding Proliferating Cell Nuclear Antigen. Circulation. 86:538-547.

12. Pickering, G., L. Weir, J. Jekanowski, and J. M. Isner. 1992. Inhibition of proliferation of human vascular smooth muscle cells using antisense oligodeoxynucleotides to PCNA. J. Am. Coll. Cardiol. 19:165A. (Abstr.)

13. Simons, M., E. R. Edelman, J. DeKeyser, R. Langer, and R. Rosenberg 1992. Antisense c-myb oligodeoxynucleotides inhibit arterial smooth muscle cell accumulation in vivo. Nature (Lond.). 359:67-70.

14. Spencer, C. A., and M. Groudine. 1991. Control of c-myc regulation in normal and neoplastic cells. Adv. Cancer Res. 56:1-48.

15. Kindy, M. S., and G. E. Sonenshein. 1986. Regulation of oncogene expression in cultured aortic smooth muscle cells: post-transcriptional control of c-myc mRNA. J. Biol. Chem. 261:12865-12868.

16. Gadeau, A. P., M. Campan, and C. Desgranges. 1991. Induction of cell cycle-dependent genes during cell cycle progression of arterial smooth muscle cells in culture. J. Cell. Physiol. 146:356-361.

17. Campan, M., C. Desgranges, A. P. Gadeau, D. Millet, and F. Belloc. 1992. Cell cycle dependent gene expression in quiescent stimulated and asynchronously cycling arterial smooth muscle cells in culture. J. Cell. Physiol. 150:493-500.

18. Bennett, M. R., G. I. Evan, and A. C. Newby. 1992. Early down-regulation of c-myc proto-oncogene in inhibition of vascular smooth muscle cell proliferation. Eur. Heart J. 13:28. (Abstr.)

19. Heikkila, R., G. Schwab, E. Wickstrom, S. L. Loke, D. H. Pluznik, R. Watt, and L. M. Neckers. 1987. A c-myc antisense oligodeoxynucleotide inhibits entry into $S$ phase but not progress from $G_{0}$ to $G_{1}$. Nature (Lond.). 328:445-449.

20. Holt, J. T., R. L. Redner, and A. W. Nienhuis. 1988. An oligomer complementary to c-myc mRNA inhibits proliferation of HL-60 promyelocytic cells and induces differentiation. Mol. Cell. Biol. 8:963-973.

21. Prochownik, E. V., J. Kukowska, and C. Rodgers. 1988. C-myc antisense transcripts accelerate differentiation and inhibit $G_{1}$ progression in murine erythroleukemia cells. Mol. Cell. Biol. 8:3683-3695.

22. Freytag, S. O. 1988. Enforced expression of the c-myc oncogene inhibits cell differentiation by precluding entry into a distinct predifferentiation state in $\mathrm{G}_{0} / \mathrm{G}_{1}$. Mol. Cell. Biol. 8:1614-1624.

23. Griep, A. E., and H. Westphal. 1988. Antisense Myc sequences induce differentiation of F9 cells. Proc. Natl. Acad. Sci. USA. 85:6806-6810.

24. Pietenpol, J. A., J. T. Holt, R. W. Stein, and H. L. Moses. 1990. Transforming growth factor beta 1 suppression of c-myc gene transcription: role in inhibition of keratinocyte proliferation. Proc. Natl. Acad. Sci. USA. 87:37583762.

25. Ebbecke, M., C. Unterberg, A. Buchwald, S. Stohr, and V. Wiegand. 1992. Antiproliferative effects of a c-myc antisense oligonucleotide on human arterial smooth muscle cells. Basic Res. Cardiol. 87:585-591.

26. Biro, S., Y. Fu, Z. Yu and S. Epstein. 1993. Inhibitory effects of antisense oligodeoxynucleotides targeting c-myc mRNA on smooth muscle cell proliferation and migration. Proc. Natl. Acad. Sci. USA. 90:654-658.

27. Penn, L. J., M. W. Brooks, E. M. Laufer, T. D. Littlewood, J. P. Morgenstern, G. I. Evan, W. M. Lee and H. Land. 1990. Domains of human c-myc protein required for autosuppression and co-operation with ras oncogenes are overlapping. Mol. Cell. Biol. 10:4961-4966.

28. Moore, J. P., D. C. Hancock, T. D. Littlewood, and G. I. Evan. 1987. A sensitive and quantitative enzyme-linked immunosorbence assay for the c-myc and N-myc oncoproteins. Oncogene Res. 2:65-80.

29. Clowes, A. W., M. A. Reidy, and M. M. Clowes. 1983. Kinetics of cellular proliferation after arterial injury. I. Smooth muscle growth in the absence of endothelium. Lab. Invest. 49:327-333.

30. Chirgwin, J. M., A. E. Przybyla, R. J. MacDonald, and W. J. Rutter. 1979. Isolation of biologically active ribonucleic acid from sources enriched in ribonuclease. Biochemistry. 18:5294-5299.

31. Stone, J., T. de Lange, G. Ramsay, E. Jakobovits, J. M. Bishop, H. Varmus, and W. Lee. 1987. Definition of regions in human c-myc that are involved in transformation and nuclear localization. Mol. Cell. Biol. 7:1697-709.

32. Waters, C. M., T. D. Littlewood, D. C. Hancock, J. P. Moore, and G. I Evan. 1991. c-myc protein expression in untransformed fibroblasts. Oncogene. 6:797-805.

33. Colman, A. 1990. Antisense strategies in cell and developmental biology. J. Cell Sci. 97:399-409.

34. Woolf, T. M., D. A. Melton, and C. G. B. Jennings. 1992. Specificity of antisense oligodeoxynucleotides in vivo. Proc. Natl. Acad. Sci. USA. 89:73057309.

35. Miano, J. M., R. R. Tota, N. Vlasic, K. J. Danishefsky, and M. B. Stemerman. 1990. Early proto-oncogene expression in rat aortic smooth muscle cells following endothelial removal. Am. J. Pathol. 137:761-765.

36. Bauters, C., P. de Groote, M. Adamantidis, C. Delcayre, M. Hamon, J. M Lablanche, M. E. Bertrand, B. Dupuis, and B. Swynghedauw. 1992. Proto-oncogene expression in rabbit aorta after wall injury: first marker of the cellular process leading to restenosis after angioplasty? Eur. Heart J. 13:556-559. 